\title{
ORIGINAL ARTICLE Feelings of burden among family caregivers of people with spinal cord injury in Turkey
}

\author{
E Secinti ${ }^{1}, \mathrm{HM}$ Yavuz $^{2}$ and B Selcuk ${ }^{3}$
}

Study design: The study was designed as a cross-sectional survey.

Objectives: The purpose of the study was to examine the level of feelings of burden in family caregivers of people with spinal cord injury $(\mathrm{SCl})$ in Turkey, and to explore its predictors.

Setting: Turkey.

Methods: One hundred family caregivers of people with SCl completed measures of burden of caregiving, depression, social support and physical health. The SCl participants completed a measure of functional independence. Multivariate statistics and structural equation modeling (SEM) were conducted to identify significant predictors of caregiver burden.

Results: Caregiver burden was significantly related to caregivers' feelings of depression. SEM analysis showed that social support from family and from friends predicted caregiver burden via depression. Caregivers' age, sex, educational level, physical health and household income did not significantly predict their feelings of depression or burden.

Conclusions: Our findings revealed that support received from both families and friends is an important source for alleviating the depressive feelings of caregivers and, in return, their burden in the caregiving. In Turkey, high support from family members is expected and is important for psychological well-being, yet the current study showed that the support received from friends also has unique contribution to the well-being of the caregivers of persons with $\mathrm{SCl}$. Overall, our findings highlight the importance of supportive relationships between family as well as friends for the caregivers who may have to provide lifetime care for their family member with special needs.

Spinal Cord (2017) 55, 782-787; doi:10.1038/sc.2017.6; published online 7 February 2017

\section{INTRODUCTION}

Spinal cord injury (SCI) is a debilitating condition that affects bodily functions, which can leave individuals in need of ongoing assistance and care in activities of daily living. Generally, regardless of the level of development in a country, a family member assumes the role of the caregiver for the person with SCI (refs 1,2; also for review see ref. 3). Family caregivers operate as informal health-care providers, and they provide this assistance for an indefinite period of time. ${ }^{4-6}$ Yet they usually have inadequate education for such assistance, and this may affect their interpersonal relations, employment status, physical and psychological health, and cause increased feelings of burden. ${ }^{2,5,7-9}$ On the bright side, the social support the caregivers received was previously found to ameliorate these negative outcomes. ${ }^{10-12}$ In Turkey, general infrastructure and government assistance for disabled individuals are inadequate; therefore, caregiving is even more important and challenging, and family caregivers take on considerable responsibility providing care to their family member with SCI. ${ }^{13}$ The current study aims to examine feelings of burden among caregivers in Turkey and the factors associated with this feeling including: caregivers' level of depression, physical health, and their received social support. Unlike prior research, in the current study we measured the support received from different sources (for example, from friends and family members) in order to investigate whether the source of support is differentially influential.

A growing body of literature has focused on identifying the factors associated with caregiver burden. Two factors that have been found to be linked to caregiver burden are the caregivers' feelings of depression and their received social support. Findings indicate that family caregivers with higher levels of depression feel elevated levels of burden. ${ }^{1,9,12}$ However, receiving social support is a protective factor for feelings of depression and burden, and helps caregivers to be more satisfied with their lives. ${ }^{10-12}$ In previous studies, support is conceptualized and measured as a unitary construct, and the possible unique role of different sources of support, such as support received from friends or family, is not investigated. However, in cultures where emotional closeness and tight support networks among family members are valued more highly, people turn more to their family for support, and familial cohesion might play a critical role in alleviating distress.

In Turkey, emotional closeness among family members is expected, and there are tight networks of support and daily contact between members of the family and close relatives. ${ }^{14}$ Therefore, turning to family for support can be quite common to alleviate feelings of distress and burden. Although family support is often normative and ordinary in Turkey, support received from extra-familial sources such as friends

${ }^{1}$ Department of Psychology, Indiana University_Purdue University Indianapolis, Indianapolis, IN, USA; ${ }^{2}$ Department of Psychology, MEF University, Istanbul, Turkey and ${ }^{3}$ Department of Psychology, Koç University, Istanbul, Turkey

Correspondence: E Secinti, Department of Psychology, Indiana University_Purdue University Indianapolis, Indianapolis, IN 46202, USA.

E-mail: esecinti@iupui.edu

Received 19 June 2016; revised 29 December 2016; accepted 6 January 2017; published online 7 February 2017 
might bring a significant additional comforting advantage. To our knowledge, there are very few studies that measured the role of different sources of support in Turkish mothers. ${ }^{15}$ One study reported strong extended family and community social networks in Turkey, and showed that support from extended family and friends acted as a protective factor for positive outcomes in children. ${ }^{15}$ Nevertheless, after a thorough search of the literature, we were surprised to find no studies on the additive role of friend support in caregivers' feelings of depression or burden in caregivers of individuals with SCI. Further, although caregivers' feelings of burden have been examined in some detail, no study has simultaneously investigated the effects of depression, support from family, and support from friends on caregiver burden.

In general, caregivers are also more likely to have poor health, higher risks for mortality and greater cardiovascular and immune system problems compared with non-caregivers. ${ }^{16-19}$ However, when caregivers have better physical health, they report feeling lower levels of burden $^{18,20,21}$ and depression ${ }^{2}$ and receiving more social support. ${ }^{22,23}$ A concerning finding from Turkey indicated that SCI caregivers in particular had poorer physical health compared with non-caregivers. ${ }^{24}$

Across Turkey, there are numerous challenging problems for persons with SCI, including inadequate infrastructure, very limited wheelchair access, shortage of social services and primary-care facilities such as physical therapy and rehabilitation centers, as well as the lack of personnel with expertise in SCI. Moreover, caregivers might experience financial difficulties arising from high health-care costs for persons with $\mathrm{SCI}^{5}$ and in Turkey, families of persons with SCI receive very limited government subsidies for care (that is, less than approximately 170 US dollars per month), potentially leaving the caregivers in financial hardship. These factors are likely to exacerbate the caregivers' feelings of burden.

Following these findings, the present study aims to investigate the feelings of burden among caregivers of persons with SCI in Turkey, and to examine the roles of caregiver depression, social support from different sources, and physical health in their feelings of burden. In line with prior research (for example, 1, 5, 25), we hypothesized that higher caregiver depression and lower social support from family and from friends would be predictive of higher levels of caregiver burden. Apart from being related to burden, we predicted that support from family members and friends would be a protective factor for depression and physical health. We hypothesized that the roles of support received from friends and from family in caregiver burden could be mediated by the depression and physical health of the caregiver. Also, previous studies suggest that older, ${ }^{1,5}$ female $^{5}$ and less educated caregivers, ${ }^{24}$ with lower household income, ${ }^{12}$ who need to provide care for persons with SCI with less functional independence $e^{5,26}$ and tend to feel higher levels of caregiver burden. Thus we investigated these demographic factors as possible control variables in the current study.

\section{MATERIALS AND METHODS}

\section{Participants and recruitment}

The participants were 100 family caregivers of persons with SCI living in Turkey and their care-recipients with SCI. In this study, family caregiver is defined as the family member who was primarily responsible for immediate care of the persons with SCI. The family caregivers and the persons with SCI were recruited through hospitals, physical therapy and rehabilitation centers, disability support groups and through the internet via social media announcements.

\section{Measures}

Family caregivers completed questionnaires that measured their feelings of burden, depression, physical health and the support they received from their family members and from their friends. Their care-recipient relatives with SCI completed a background information form and a scale that assessed their own functional independence level.

Background information. Participants with SCI completed a form providing descriptive information about themselves (for example, age, sex, education, marital status), their condition (for example, type of injury, onset, cause of SCI) and their family members (for example, age, sex, education, income, marital status).

Caregiver burden. Caregiver burden was measured with the Burden Assessment Scale. ${ }^{27}$ Burden Assessment Scale has 19 items (for example, 'in the past 6 months, did you find it difficult to concentrate on your own activities because of your relative's orthopedic disability?') rated on a four-point Likert scale $(1=$ not at all, $4=$ all the time). The caregiver burden score was computed by averaging the 19 item scores (Cronbach's $\alpha=0.88$ ).

Caregiver depression. The level of depressive symptoms of the family caregivers was measured with the Beck Depression Inventory. ${ }^{28}$ This measure includes 21 items rated on a four-point Likert scale ranging from 0 to 3 . Item scores were summed to compute the caregiver depression score (Cronbach's $\alpha=0.91$ ).

Caregiver social support from family. We used the Family subscale (nine items) of the Multidimensional Scale of Perceived Social Support ${ }^{29}$ to measure the level of social support the caregivers perceived to receive from their family members. The items (for example, 'I can talk about my problems with my family') were rated on a five-point Likert scale $(1=$ absolutely true, $5=$ absolutely false), and averaged to obtain the social support from family score (Cronbach's $\alpha=0.87$ ).

Caregiver social support from friends. We used the Index of Perceived Social Support ${ }^{30}$ to measure the family caregivers' perceived social support from their friends. The scale included 10 items (for example, 'I do not have any close friends') rated on a five-point scale ( $1=$ absolutely true, $5=$ absolutely false). The scores were averaged to compute the score for support from friends (Cronbach's $\alpha=0.85$ ).

Caregiver physical health. To assess the physical health of family caregivers, we utilized the General Perception of Health component of Short Form-36 Health Survey (SF-36). ${ }^{31}$ SF-36 included five items (e.g., 'My health is excellent') rated on a five-point Likert scale $(1=$ absolutely true, $5=$ absolutely false). The scores were averaged to compute the family caregivers' physical health score (Cronbach's $\alpha=0.78$ ).

Functional independence of SCI person. Spinal Cord Independence Measure $(\mathrm{SCIM}-\mathrm{III})^{32}$ was used to assess the level of functionality of the participants with SCI. SCIM-III included items on mobility (nine items; for example, 'I need an electric wheelchair or partial assistance to operate a manual wheelchair'), self-care (four items), and respiration and sphincter management (two items). Two items on sphincter management were omitted from the scale as these questions were not applicable to the majority of the targeted sample. In the SCIM-III, the items are rated on different Likert scales ranging from 2 to 9 points (see ref. 32 for scoring), with higher scores indicating better functionality. In the present study, the functional independence score was calculated by adding the scores from 15 items (Cronbach's $\alpha=0.93$ ).

\section{Procedure}

All the measures used in this research were previously translated into Turkish, showed good psychometric properties (that is, internal consistency and validity), and used in other studies conducted in Turkey with people with SCI (SCIM-III), ${ }^{33}$ and family caregivers of the persons with SCI (Burden Assessment Scale; ${ }^{34}$ Beck Depression Inventory; ${ }^{35}$ Multidimensional Scale of Perceived Social Support and Index of Perceived Social Support; ${ }^{36}$ and SF-36: 23). 
Table 1 Sociodemographic and clinical characteristics of persons with $\mathrm{SCl}$ and their family caregivers

\begin{tabular}{|c|c|c|}
\hline & $\begin{array}{l}\text { SCl persons } \\
(\mathrm{N}=100)\end{array}$ & $\begin{array}{l}\text { Family caregivers } \\
\qquad(\mathrm{N}=100)\end{array}$ \\
\hline \multicolumn{3}{|l|}{ Sex } \\
\hline Male (\%) & $73(73.0 \%)$ & $29(29.0 \%)$ \\
\hline Female (\%) & $27(27.0 \%)$ & $71(71.0 \%)$ \\
\hline Mean age (s.d.) & $35.11(9.87)$ & $41.07(14.12)$ \\
\hline \multicolumn{3}{|l|}{ Caregiver family relation } \\
\hline Mother (\%) & - & $26(26.0 \%)$ \\
\hline Father (\%) & - & $6(6.0 \%)$ \\
\hline Spouse (\%) & - & $33(33.0 \%)$ \\
\hline Sibling $(\%)$ & - & $28(28.0 \%)$ \\
\hline Other (i.e., adult, child, niece, aunt) (\%) & - & $7(7.0 \%)$ \\
\hline \multicolumn{3}{|l|}{ Marital status } \\
\hline Married (\%) & $41(41.0 \%)$ & $71(71.0 \%)$ \\
\hline Single $(\%)$ & $53(53.0 \%)$ & $23(23.0 \%)$ \\
\hline Separated/divorced (\%) & $6(6.0 \%)$ & $6(6.0 \%)$ \\
\hline \multicolumn{3}{|l|}{ Education } \\
\hline $\begin{array}{l}\text { Illiterate/did not complete elementary } \\
\text { school (\%) }\end{array}$ & $6(6.0 \%)$ & $16(16.0 \%)$ \\
\hline Primary school graduate (\%) & $36(36.0 \%)$ & $49(49.0 \%)$ \\
\hline Secondary school graduate (\%) & $13(13.0 \%)$ & $24(24.0 \%)$ \\
\hline High school graduate (\%) & $38(38.0 \%)$ & $0(0.0 \%)$ \\
\hline University degree (\%) & $5(5.0 \%)$ & $10(10.0 \%)$ \\
\hline \multicolumn{3}{|l|}{ Employment status } \\
\hline Unemployed (\%) & $70(70.0 \%)$ & $70(70.0 \%)$ \\
\hline Employed part-time (\%) & $5(5.0 \%)$ & $7(7.0 \%)$ \\
\hline Employed full-time (\%) & $11(11.0 \%)$ & $22(22.0 \%)$ \\
\hline Student (\%) & $14(14.0 \%)$ & - \\
\hline Mean age of $\mathrm{SCl}$ onset, years (s.d.) & $25.38(10.11)$ & - \\
\hline Mean time since $\mathrm{SCl}$, years (s.d.) & $9.73(8.46)$ & - \\
\hline \multicolumn{3}{|l|}{ Spinal cord injury type } \\
\hline Paraplegia (\%) & $75(75.0 \%)$ & - \\
\hline Quadriplegia (\%) & $25(25.0 \%)$ & - \\
\hline \multicolumn{3}{|l|}{ Causes of spinal cord injury } \\
\hline Motor vehicle accidents (\%) & $35(35.0 \%)$ & - \\
\hline Fall from heights $(\%)$ & $22(22.0 \%)$ & - \\
\hline Gunshot (\%) & $11(11.0 \%)$ & - \\
\hline Shallow river/ sea dive (\%) & $5(5.0 \%)$ & - \\
\hline Not reported (\%) & $27(27.0 \%)$ & - \\
\hline
\end{tabular}

Abbreviation: $\mathrm{SCl}$, spinal cord injury.

Data were collected after getting the approval of the University Institutional Review Board and written informed consents of all the participants (that is, both family caregivers and their relatives with SCI). The questionnaires were administered one-on-one to the family caregivers (lasting about $15 \mathrm{~min}$ ) and the participants with SCI (lasting about $5 \mathrm{~min}$ ).

We certify that all applicable institutional and governmental regulations concerning the ethical use of human volunteers were followed during the course of this research.

\section{RESULTS}

The participants were residing in 12 different cities located in five districts of Turkey. Family caregivers were mostly (87\%) mothers,
Table 2 Descriptive statistics $(N=100)$

\begin{tabular}{lrrrr}
\hline Variable & M & s.d. & Min & Max \\
\hline Caregiver burden (1-4) & 2.02 & 0.60 & 1.00 & 3.53 \\
Caregiver depression (0-63) & 11.71 & 10.52 & 0.00 & 44.00 \\
Caregiver social support from family (1-5) & 4.07 & 0.86 & 1.67 & 5.00 \\
Caregiver social support from friends (1-5) & 3.41 & 0.90 & 1.20 & 5.00 \\
Caregiver physical health (1-5) & 3.39 & 0.79 & 1.40 & 4.80 \\
Functional independence of SCl person (0-75) & 39.81 & 13.13 & 12.00 & 61.00 \\
\hline Abbreviation: SCl, spinal cord injury & & & &
\end{tabular}

Abbreviation: $\mathrm{SCl}$, spinal cord injury.

Table 3 Zero-order correlations between study variables $(N=100)$

\begin{tabular}{|c|c|c|c|c|c|}
\hline & 1 & 2 & 3 & 4 & 5 \\
\hline 1. Caregiver burden & - & & & & \\
\hline 2. Caregiver depression & $0.50^{* * *}$ & - & & & \\
\hline $\begin{array}{l}\text { 3. Caregiver social support from } \\
\text { family }\end{array}$ & $-0.25^{*}$ & $-0.41^{* * *}$ & - & & \\
\hline $\begin{array}{l}\text { 4. Caregiver social support from } \\
\text { friends }\end{array}$ & $-0.39 * * *$ & $-0.47^{* * *}$ & $0.20^{*}$ & - & \\
\hline 5. Caregiver physical health & -0.19 & $-0.37^{* * *}$ & $0.34^{* *}$ & $0.29^{* *}$ & - \\
\hline $\begin{array}{l}\text { 6. Functional independence of } \\
\mathrm{SCl} \text { person }\end{array}$ & $-0.20^{*}$ & -0.10 & -0.04 & 0.17 & -0.07 \\
\hline
\end{tabular}

spouses or siblings of the persons with SCI. Age of caregivers ranged from 15 to 63 years. Of the family caregivers, the majority were female, married, had not graduated from high school and were unemployed (see Table 1). Most of the families (81\%) had low household income (that is, less than approximately 840 US dollars per month) with $67 \%$ earning below minimum wage (that is, less than approximately 560 US dollars per month).

Age of care-recipients with SCI ranged from 16 to 58 years. Over half of them were single; the majority had not graduated from high school, and were unemployed. Motor vehicle accidents and fall from heights were common causes of SCI (see Table 1), and majority of them had paraplegia. We were unable to access information about the injury severity (for example, ASIA level) and completeness of injury of persons with SCI as this information is available mostly to physicians in Turkey, and persons with SCI or their caregivers are not informed about their injury in detail. Instead we measured functional independence of persons with SCI and were able to infer to the severity of injury by the functional limitations individuals were experiencing. Time since injury varied between 0.40 and 37.83 years with a median of 7.46 years and a mean of 9.73 years $($ s.d. $=8.46)$.

\section{Caregiver outcomes}

Descriptive statistics for the study variables are provided in Table 2. Analysis of variance results showed that caregivers' sex was not related to their feelings of burden $(F(1,98)=0.39, P=0.53)$, level of depression $(F(1,98)=2.28, P=0.13)$, physical health $(F(1,98)=0.26, P=0.61)$, social support they receive from family $(F(1,98)=0.13, P=0.72)$, and social support they receive from friends $(F(1,98)=0.00, P=0.95)$.

Zero-order correlations (see Table 3$)$ revealed that age $(r=0.03$, $P=0.77)$, education level $(r=-0.15, P=0.14)$, employment status $(r=0.12, P=0.24)$ and physical health $(r=-0.19, P=0.06)$ of the caregivers did not have a significant correlation with their level of 


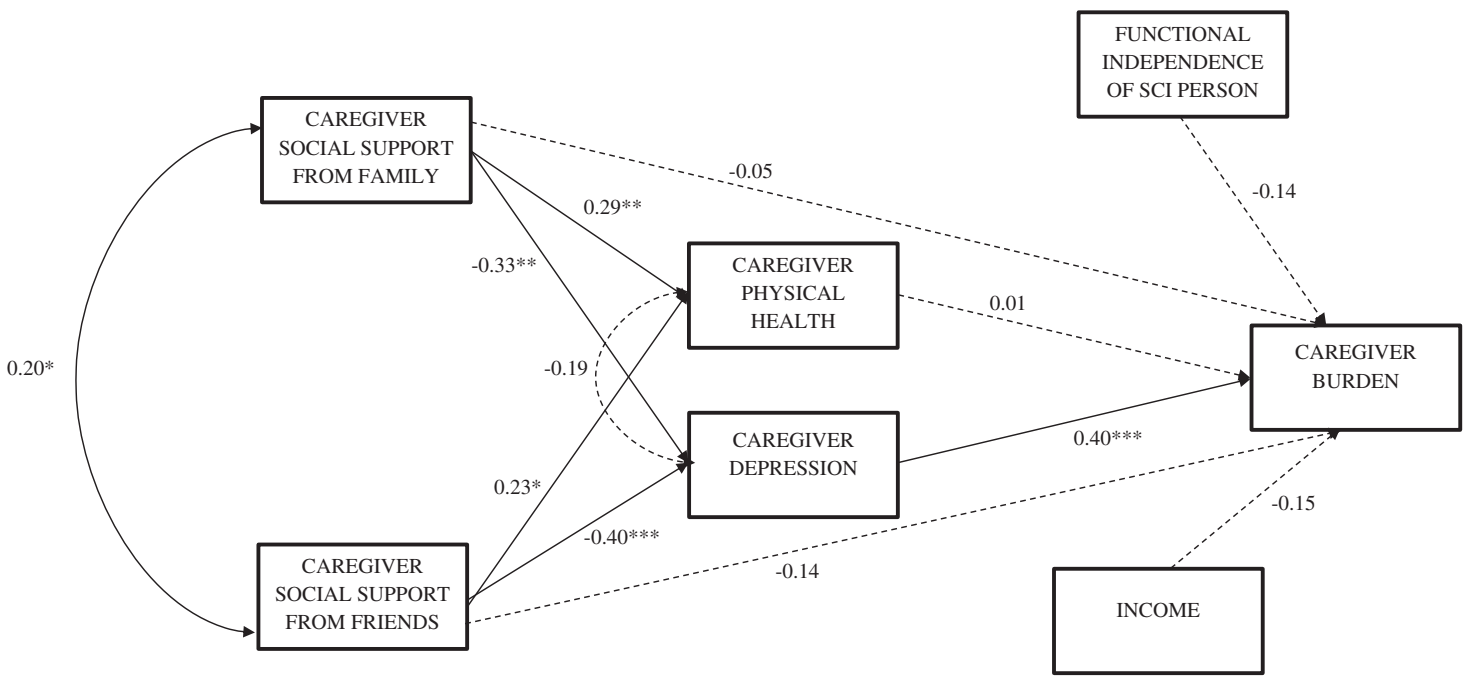

Figure 1 The hypothesized model predicting caregiver burden. Note: ${ }^{*} P<0.05 ;{ }^{*} P<0.01$; ${ }^{* *} P<0.001$. The dashed lines represent hypothesized but nonsignificant paths, and solid lines represent the significant paths.

caregiving burden. Income was significantly and negatively associated with caregiver burden in the correlational results $(r=-0.25, P<0.05)$.

Functional independence of the persons with SCI, social support from family and social support from friends were negatively, and caregiver's depression was positively associated with caregiver burden (see Table 3). More specifically, higher depression, lower social support from family and from friends, lower household income and less functional independence of the persons with SCI were associated with higher levels of caregiver burden.

The association between physical health and depression of caregiver was negative, and the association between social support from family members and social support from friends was positive. Caregivers' social support from family and from friends were strongly and negatively correlated with their depression (see Table 3 ).

\section{The hypothesized model}

We conducted the model testing using Mplus 6.12 (Muthen \& Muthen, Los Angeles, CA, USA). ${ }^{37}$ with maximum likelihood estimation for parameters, and the bias-corrected bootstrapping method, as it is recommended when testing mediation with sample sizes $<400$. $^{38}$

On the basis of the previous research we built a conceptual model, in which we proposed that caregiver's social support from family and from friends would be indirectly associated with the family caregivers' feelings of burden via caregivers' depression (see Figure 1). Moreover, we proposed that social support from family and from friends would be directly associated with caregiver health. We also tested the direct links from social support from family, social support from friends and caregiver health and depression to feelings of burden. The model controlled for the role of income and functional independence of the persons with SCI in caregiver burden as well.

The results of path analysis showed that the fit of the model was good, $\chi^{2}(8, N=100)=14.63, p=0.07, C F I=0.92, R M S E A=0.09$, $90 \%$ confidence interval $=(0.00-0.16)$ and $S R M R=0.08$. As can be seen in Figure 1, both support from family and support from friends significantly and negatively predicted caregiver's depression, whereas caregiver health did not have a significant association with depression. Both support from family and support from friends significantly and positively predicted caregiver health. Functional independence of the person with SCI and income did not predict burden of caregiving in the path analysis. Caregiver burden was predicted by caregiver depression, but not by social support from family or friends directly. Higher social support from family members was associated with higher social support from friends.

To examine indirect effects of friend and family support on caregiver burden via depression, we used bootstrapping (on 2000 samples), estimated the bias-corrected bootstrap standard errors and obtained 95\% confidence intervals for the estimates. The results indicated that both the link from social support from family to caregiving burden $\left(\beta=-0.13 ; \beta_{\text {standard error }}=0.05 ; \% 95\right.$ confidence interval $=-0.23$ to $-0.03 ; P<0.05)$ and the one from social support from friends $\left(\beta=-0.16 ; \beta_{\text {standard error }}=0.05 ; \% 95\right.$ confidence interval $=-0.27$ to $-0.05 ; \quad P<0.01)$ to caregiving burden were mediated via caregiver depression, indicating that higher support received from family and friends predicted less burden in caregivers via lowing their depressive feelings.

To examine the strength of the relations between caregiver depression and support from family, and caregiver depression and support from friends, we conducted additional analyses. Specifically, structural equation modeling analyses were run twice, once when these two paths were set equal to each other (that is, constrained model) and once with the original hypothesized model (that is, without constraints). The constrained model assumed that the link from support from family to caregiver depression did not statistically differ from the link from support from friends to caregiver depression. In the current analysis, the constrained model and the model without constraints did not differ from each other $\left(\Delta \chi^{2}(1)=0.16, n s\right)$, indicating that the two models were equal, and the predictive power of support from family and support from friends for caregiver depression were similar.

\section{DISCUSSION}

In this study, our primary focus was to examine caregivers' burden and its relations with their depression, health and the social support that they receive from different sources. Feelings of burden among SCI caregivers is a risk factor associated with low quality of life and increased mortality. ${ }^{16-19}$ In underdeveloped or developing countries like Turkey, due to inadequate infrastructure and limited social 
services and facilities, family caregivers are primarily responsible for providing care for their family members with SCI, which might lead to elevated feelings of burden.

The results showed that an important predictor for the caregiver burden was the depression level of the caregiver; caregivers who reported more depression also reported more burden in their caregiving role. These findings are consistent with prior findings indicating that when caregivers feel depressed and have poorer psychological well-being, they experience greater caregiving burden. ${ }^{1,10,25}$ Caregivers need to provide assistance to persons with SCI in their daily activities including feeding, dressing, transfer, and bowel and bladder care. ${ }^{3,11}$ Due to their time-consuming and tiring caregiving duties, caregivers might feel like they have no time to themselves. As a result, they might feel fatigued and depressed in their caregiving role. Depressive feelings might influence caregivers' overall appraisal of the situation and may make them perceive the situation as more negative. With this heightened negative perception, caregivers might also perceive their caregiving duties as even more overwhelming. Hence, their negative thought processes (for example, hopelessness) might increase their feelings of burden in their caregiving role. These findings show that depressive feelings are an important target for interventions to decrease burden in caregivers.

Although current findings showed depression is an important risk factor for feelings of burden, our results also showed that social support from family and friends is an important resource for alleviating depressive feelings, and in turn, burden among caregivers. Hence, in line with the previous literature, ${ }^{1,5,12}$ our results showed that support received from others is an important protective factor that buffers depressive feelings in caregivers. Previous studies suggested that when caregivers perceive the people in their close circle as available to provide aid, they feel less depressed. ${ }^{11}$ The results of the current study extended the previous findings by suggesting that higher support related to lower level of depression is a protective factor for the feelings of burden in caregivers. Therefore, feeling less socially supported by their family members and friends, caregivers reported feeling more depressed, which in turn led to elevated feelings of burden. This finding is important because it clarifies how social support helps alleviate burden experienced by caregivers of people with SCI.

Another important aim of the current study was to investigate whether or not the social support received from different sources would have differential influences on the reduction or prevention of burden and depression associated with caregiving. In contrast to our expectations, support from family and friends was equally effective in decreasing depressive feelings in caregivers, suggesting that any type of support is valuable in alleviating depressive feelings and, indirectly, burden. In Turkey, deep family reliance is widely observed, with strong and close emotional ties between family members. Valuing needs of family members over personal needs and self-sacrifice is strongly reinforced as the social system does not provide extensive institutions to take responsibility for its dependent people such as the disabled and elderly. ${ }^{14}$ Hence, in Turkey, family bonds are strong and support from family might be taken for granted. On the other hand, support from non-family sources, such as friends, is also valuable. ${ }^{14,15}$ Therefore, current findings suggest that the presence of support, regardless of the source, might be an important factor for the wellbeing of caregivers, and receiving multiple sources of support may have additive effects to ameliorate well-being in caregivers. Since caregivers generally need to provide lifetime care for their family member with SCI, which is a task for which they are not prepared or experienced, the support from any person might be highly valuable. Indeed, in a study conducted in South Africa, a country with low levels of infrastructure for disabled individuals, caregivers reported that one of their most frequent needs was the support they received from their family and friends. ${ }^{10}$ These findings are echoed in the current results, revealing that support from others is an important protective factor for caregiver depression and, in return, burden.

In contrast to our expectations, caregivers' health status, sex, age or education level, and the functional independence of the persons with SCI were not related to their levels of burden. Although correlation analyses suggested income was associated with caregiver burden, path analyses indicated that when factors such as social support and depression were added to the model, income was not predictive of caregiver burden. Yet, these results were in line with the argument of Rodakowski et al., ${ }^{12}$ which stated that regardless of the demographic factors, caregiving for a person with SCI is a distressing experience, and caregivers feel burdened by their responsibilities. Therefore, it is plausible that instead of demographic factors, the social support from friends and families, and the level of depression in the caregiver might be more important factors for the perceived burden in the caregiving role.

\section{Strengths and limitations}

To our knowledge this was the first study to investigate the predictors of caregiver burden focusing on multiple factors including caregiver depression, health, and social support from family, and social support from friends among family caregivers of persons with SCI in Turkey. By measuring social support from different sources and exploring the mediational role of caregiver depression, our results provide important information about the factors related to family caregivers' feelings of burden in Turkey and the influence of supportive networks among family members and friends of SCI caregivers.

The results should be evaluated in context of some limitations. Due to the cross-sectional nature of the data, these findings do not imply causation and do not provide information about the direction of the effects. Although structural equation modeling model implies the direction of effects, we formed the model based on previous literature and discuss our findings with respect to prior research. Also, even though the demographics of our sample was similar to other studies (for example, 5, 12), we must note that it consisted mostly of female family caregivers, with relatively low education, who were unemployed, and providing care mostly for individuals with paraplegia. These may have limited the variance in the data and the generalizability of the results. For future research, it is important that these findings are replicated with larger and more diverse samples. In Turkey, there are important problems in infrastructure that limits the quality of life and functional independence of people with SCI, and the governmental support for SCI persons and their families is very limited. These factors might be leading to even higher burden in caregivers in Turkey as opposed to other countries with better facilities. For future research, it might be beneficial to investigate the relative differences in caregivers' feelings of burden in low- and highresource countries for a better understanding of caregivers' needs.

\section{Implications}

The persons with SCI who live in Turkey are in need of constant assistance in activities of daily living because of the limited infrastructure for independent functioning and shortage of social services in this country. Although caregiving to a person with SCI is burdensome on its own, such problems might impose even more trouble to persons with SCI and their caregivers, and this might contribute to Turkish caregivers' feelings of burden as it has been documented in other developing countries. ${ }^{1}$ 
Findings of this study have important implications for clinical care and rehabilitation for the family caregivers of persons with SCI. Similar to previous studies; ${ }^{1,10}$ current results showed that caregiver depression is a very important factor that needs to be alleviated when targeting burden in caregivers. Previous research suggests ${ }^{2}$ that interventions aimed at improving social support, quality of life or coping with depression could help caregivers feel less burdened by their caregiving role. Extending these findings, our results indicate that interventions promoting social support from friends or family would be helpful for Turkish caregivers' psychological well-being via diminishing their feelings or depression and indirectly diminishing their feelings of burden.

\section{DATA ARCHIVING}

There were no data to deposit.

\section{CONFLICT OF INTEREST}

The authors declare no conflict of interest.

1 Gajraj-Singh P. Psychological impact and the burden of caregiving for persons with spinal cord injury (SCI) living in the community in Fiji. Spinal Cord 2011; 49: 928-934.

2 Schulz R, Czaja SJ, Lustig A, Zdaniuk B, Martire LM, Perdomo D. Improving the quality of life of caregivers of persons with spinal cord injury: a randomized controlled trial. Rehabil Psychol 2009; 54: 1-15.

3 Adelman RD, Tmanova LL, Delgado D, Dion S, Lachs MS. Caregiver burden: a clinical review. JAMA 2014; 311: 1052-1060.

4 Elliott TR, Shewchuk RM, Richards JS. Caregiver social problem-solving abilities and family member adjustment to recent-onset physical disability. Rehabil Psychol 1999; 44: 104-123.

5 Post MWM, Bloemen J, de Witte LP Burden of support for partners of persons with spinal cord injuries. Spinal Cord 2005; 43: 311-319.

6 Robinson-Whelen S, Rintala DH. Informal care providers for veterans with $\mathrm{SCl}$ : who are they and how are they doing? J Rehabil Res Dev 2003; 40: 511-516.

7 Atagun MI, Altinok U, Balaban OD, Atagun Z, Yilmaz-Yalcinkaya E, Ones K. Caregiver burden in chronic diseases. Current Approaches in Psychiatry 2012; 15: 92-102.

8 Boschen KA, Tonack M, Gargaro J. The impact of being a support provider to a person living in the community with a spinal cord injury. Rehabil Psychol 2005; 50: 397-407.

9 Middleton JW, Simpson GK, De Wolf A, Quirk R, Descallar J, Cameron ID. Psychological distress, quality of life, and burden in caregivers during community reintegration after spinal cord injury. Arch Phys Med Rehab 2014; 95: 1312-1319.

10 Arango-Lasprilla JC, Olivera Plaza SL, Drew A, Perdomo Romeroc JL, Arango Pizarrob $\mathrm{JA}$, Francis $\mathrm{K}$ et al. Family needs and psychosocial functioning of caregivers of individuals with spinal cord injury from Colombia, South America. NeuroRehabilitation 2010; 27: 83-93.

11 Morlett-Paredes A, Perrin PB, Olivera SL, Rogers HL, Perdomo JL, Arango JA et al. With a little help from my friends: social support and mental health in $\mathrm{SCl}$ caregivers from Neiva, Colombia. NeuroRehabilitation 2014; 35: 841-849.

12 Rodakowski J, Skidmore ER, Rogers JC, Schulz R. Role of social support in predicting caregiver burden. Arch Phys Med Rehab 2012; 93: 2229-2236.

13 Survey on Problems and Expectations of Disabled People. Turkish Statistical Institute: Turkey, Turkey. 2010.
14 Kagitcibasi C. Family, Self, and Human Development Across Cultures: Theories and applications, 2nd ed. Lawrence Erlbaum Associates Publishers: Mahwah, NJ, USA 2007.

15 Baydar N, Kuntay AC, Yagmurlu B, Aydemir N, Cankaya D, Goksen F et al. 'It takes a village' to support the vocabulary development of children with multiple risk factors. Dev Psychol 2014; 50: 1014-1025.

16 Chan RC, Lee PW, Lieh-Mak F. Coping with spinal cord injury: personal and marital adjustment in the Hong Kong Chinese setting. Spinal cord 2000; 38: 687-696.

17 Elliott TR, Berry JW. Brief problem-solving training for family caregivers of persons with recent-onset spinal cord injuries: a randomized controlled trial. J Clin Psychol 2009; 65: 406.

18 Donelan K, Hill CA, Hoffman C, Scoles K, Feldman PH, Levine C et al. Challenged to care: informal caregivers in a changing health system. Health Aff (Millwood) 2002; 21: 222-231.

19 LaVela SL, Landers K, Etingen B, Karalius VP, Miskevics S. Factors related to caregiving for individuals with spinal cord injury compared to caregiving for individuals with other neurologic conditions. J Spinal Cord Med 2015; 38 505-514.

20 Nogueira PC, Rabeh SAN, Caliri MHL, Haas VJ. [Caregivers of individuals with spinal cord injury: caregiver burden]. Rev ESC Enferm USP. 2013; 47: 607-614.

21 Cohen S. Social Relationships and Health. Am Psychol 2004; 59: 676-684.

22 Pinquart M, Sörensen S. Correlates of physical health of informal caregivers: a metaanalysis. J Gerontol B Psychol 2007; 62 (2): 126-137.

23 Unalan H, Gencosmanoglu B, Akgun K, Karamehmetoglu S, Tuna H, Ones K et al. Quality of life of primary caregivers of spinal cord injury survivors living in the community: controlled study with short form-36 questionnaire. Spinal Cord 2001; 39 . 318-322.

24 Vagharseyyedin SA, Molazem Z Burden, resilience, and happiness in family caregivers of spinal cord injured patients. ME-JPA 2013; 4: 29-35.

25 Schulz R, Beach SR. Caregiving as a risk factor for mortality: the Caregiver Health Effects Study. JAMA 1999; 282: 2215-2219.

26 Schulz R, Tompkins CA, Wood D, Decker S. The Social Psychology of Caregiving: Physical and Psychological Costs of Providing Support to the Disabled1. J App/ Soc Psychol 1987; 17: 401-428.

27 Reinhard SC, Gubman GD, Horwitz AV, Minsky S. Burden Assessment Scale for families of the seriously mentally ill. Eval Program Plann 1994; 17: 261-269.

28 Beck AT, Ward CH, Mendelson M, Mock J, Erbaugh J. An inventory for measuring depression. Arch Gen Psychiat 1961; 4: 561-571.

29 Zimet GD, Dahlem NW, Zimet SG, Farley GK. The Multidimensional Scale of Perceived Social Support. J Pers Assess 1988; 52: 30-41.

30 Henderson S, Duncan-Jones P, McAuley H, Ritchie K. The patient's primary group. Brit $J$ Psychiat 1978; 132: 74-86.

31 Ware JE, Snow KK, Kosinski M, Gandek B. SF-36 ${ }^{\circledR}$ Health Survey Manual and Interpretation Guide. The Health Institute: Boston, MA, USA. 1993.

32 Fekete C, Eriks-Hoogland I, Baumberger M, Catz A, Itzkovich M, Luthi $\mathrm{H}$ et al. Development and validation of a self-report version of the Spinal Cord Independence Measure (SCIM III). Spinal Cord 2013; 51: 40-47.

33 Kesiktas N, Paker N, Bugdayci D, Sencan S, Karan A, Muslumanoglu L. Turkish adaptation of Spinal Cord Independence Measure - version III. Int J Rehabil Res 2012; 35: 88-91.

34 Aydemir O, Dikici D, Akdeniz F, Kalayci F. Reliability and validity of the Turkish version of the burden assessment scale. Arch Neurpsychiat 2012; 49: 276.

35 Dereli F, Okur S. Determination of the depression level of the families having a handicapped child. New J Med 2008; 25: 164

36 Yagmurlu B, Yavuz HM, Sen H. Well-being of mothers of children with orthopedic disabilities in a disadvantaged context: findings from Turkey. J Child Fam Stud 2015; 24: 948-956.

37 MPlus (Version 6.12).. Muthen \& Muthen: Los Angeles, CA, USA.

38 McCartney K, Burchinal MR, Kristen LB. Best practices in quantitative methods for developmentalists. Monogr Soc Res Child 2006; 71: i-145. 